\title{
A UNIVERSIDADE BRASILEIRA DO SÉCULO XXI
}

Rodolfo Joaquim Pinto da Luz

Reitor e Professor

Universidade Federal de Santa Catarina

\author{
Palestra proferida na abertura do \\ XI SEMINÁRIO NACIONAL DE BIBLIOTECAS UNIVERSITÁRIAS: A \\ BIBLIOTECA UNIVERSITÁRIA DO SÉCULO XXI, 24 a 28 de abril de 2000
}

Os desafios que se impõem à Universidade Brasileira no início do século XXI, não serão outros que aqueles enfrentados nos últimos anos do século $\mathrm{XX}$, e tampouco se diferenciarão de forma significativa no cenário latino-americano e dos países em desenvolvimento, entretanto, há de considerar-se que o processo acelerado de mudanças da humanidade exige transformações e renovações cada vez mais rápidas.

Ao discutirmos a Universidade Brasileira devemos lembrar-nos de que a educação superior é um serviço público e de que a universidade pública cumpre um papel essencial no Brasil e na América Latina. Para atender os desafios que se impõem neste próximo século em que as sociedades dependerão, principalmente, da sua capacidade de gerar e lidar com os novos conhecimentos, adaptando-se de forma compatível à rapidez dos progressos das novas tecnologias da informação e da comunicação, faz-se necessário, basicamente, enfrentarmos a questão do financiamento da educação superior e da educação como um todo. Este é um desafio para todas as sociedades, mas, para aquelas emergentes ou em desenvolvimento, constitui-se em questão estratégica ligada à sua própria sobrevivência.

No limiar de um novo século, a maioria dos países da América Latina e do Caribe não cumpriram a meta fixada pelos Ministros da Educação na reunião do México, em 1979, de assegurar pelo menos 7\% do PIB para a educação (ensino básico, médio e superior), como única forma de garantir um desenvolvimento humano sustentável. Lembramos aqui, como importante, a proposta do Dr. Luis Yarzábal, Diretor do Instituto Internacional para a Educação Superior na América Latina e Caribe, ao se pronunciar na "Cimeira IberoAmericana de Reitores de Universidades Estatais", em agosto deste ano, na Universidade de Santiago do Chile, de destinar 5\% para a educação básica e média e $2 \%$ para a educação superior, acrescentando $2 \%$ do PIB para investimentos em pesquisa e desenvolvimento. 
Embora a questão do financiamento e dos investimentos na educação superior e na educação seja precedente, há de se buscar, também, a eficácia na gestão dos recursos e na administração dos mesmos pelos órgãos gestores nacionais, regionais e no âmbito das instituições de ensino superior. Para as últimas, a autonomia para tratar de seus assuntos e gerir seus recursos é fundamental para a eficácia da sua administração.

Tratando-se do financiamento da educação superior, requer especial atenção o financiamento das universidades públicas, pelo papel que desempenham no Brasil, onde respondem por aproximadamente $90 \%$ dos pesquisadores e projetos de pesquisa da região.

Embora compreendamos que o Estado deva ter função essencial neste financiamento, cabe à sociedade como um todo responsabilidade e atenção ao financiamento da educação em todos os níveis, aí se incluindo a educação superior e as universidades públicas. Em contrapartida, porém, é necessário, também, que as instituições de ensino superior assumam, como parte integrante da sociedade e como agentes da educação superior, a iniciativa das ações necessárias para mobilização da sociedade que as mantém e à qual servem. Tal mobilização somente pode ocorrer com a sensibilização e participação dos cidadãos, dos setores da economia, dos meios de comunicação, dos parlamentares, das organizações governamentais e não governamentais, dos estudantes e seus familiares, enfim, de todos os agentes sociais envolvidos. Estimular a abordagem do tema e a percepção do papel desempenhado pelo ensino superior e a educação em todos os níveis como condição necessária ao desenvolvimento econômico, social e cultural sustentável deve constituir-se em uma das atribuições da Universidade e da comunidade acadêmica.

Obviamente, a sensibilização e conseqüente mobilização da sociedade em apoio à educação superior e às universidades pressupõe um forte vínculo advindo da pertinência, isto é, da adequação entre o que a sociedade espera das universidades e o que elas efetivamente fazem.

No documento "Plano de Ação para a Transformação da Educação Superior na América Latina e Caribe", de março de 1998, preparado pelo Centro Regional para Educação Superior na América Latina e Caribe (CRESALC) da UNESCO, estão contempladas algumas ações estratégicas para melhoria da pertinência que, no nosso entendimento, mereceem destaque. Citamos:

- propiciar estudos, de forma contínua, visando propor soluções ao problema do acesso e do abandono dos estudos por parte dos segmentos com menos recursos; 
- preparar instrumentos que aumentem a vinculação entre a educação pré-escolar, fundamental e média com a educação superior, assim como entre os distintos subsistemas entre si;

- instrumentar novos programas de estudo que, a médio prazo, assegurem uma educação pós-secundária universal de qualidade;

- oferecer cursos profissionais de curta duração que aumentem as possibilidades de inserção no mercado de trabalho e que, numa perspectiva de educação recorrente, permitam a continuidade dos estudos;

- incentivar a criação de cursos de pós-graduação, programas de educação não formal e cursos de atualização que traduzam em realidade a educação continuada.

- preparar planos de difusão da produção e das pesquisas realizadas nas universidades, mostrando com clareza os benefícios sociais e econômicos que oferecem, com o objetivo de facilitar a avaliação por parte da sociedade e buscar o apoio de novos agentes sociais.

Esta última ação estratégica é de fundamental importância e constitui-se em dupla obrigação, primeiro como prestação de contas à sociedade e, em segundo lugar, como meio de sensibilizá-la para a importância do trabalho desenvolvido.

Importantes e necessárias são também as ações para a redução da evasão escolar e para assegurar a educação continuada para todos os segmentos da sociedade.

Cumpre-nos destacar como essencial a recomendação da Conferência Mundial sobre a Educação Superior, realizada em 1999, em Paris, de que a educação superior deve reforçar suas funções de serviço à sociedade e, mais concretamente, suas atividades dirigidas a erradicar a pobreza, a intolerância, a violência, o analfabetismo, a fome, a deterioração do meio ambiente e as doenças, principalmente mediante propostas de estudos interdisciplinares e transdisciplinares. Em que se considere o caráter universal da educação superior, a universidade latino-americana não pode ignorar estes problemas da sociedade que a mantém e na qual está inserida. Além do mais eles são, também, problemas de toda a humanidade.

Principalmente para as universidades públicas da América-Latina, inseridas em países emergentes e em desenvolvimento, detentoras do maior contingente regional de pesquisadores e com enorme responsabilidade social, o caráter da pertinência é essencial para que se estabeleçam vínculos de responsabilidade recíproca com a sociedade.

Melhorar a pertinência implica, também, ações que reforcem a cooperação com o mundo do trabalho e a análise e a previsão das necessidades da sociedade. 
A universidade deve reforçar a cooperação com o mundo laboral e a análise e a previsão das necessidades da sociedade, ampliando suas relações com as empresas e o mercado de trabalho. Cabe, entretanto, a ressalva lembrada pela Profa. Céline Saint-Pierre, Presidente do Conselho Superior da Educação de Quebec, Canadá, em sua conferência “ $O$ Ensino Superior e Seu Papel Essencial no Desenvolvimento Humano" proferida na Conferência Mundial sobre a Educação Superior:

"Há que reafirmar-se que a missão central do ensino superior é a formação e educação orientada para uma visão de longo prazo, e não só para uma busca de adaptação às necessidades imediatas do mercado de trabalho; não se pode deixar de considerar também projetos de formação e educação dentro de uma perspectiva de desenvolvimento pessoal e de preparação dos indivíduos para sua contribuição ao desenvolvimento social e econômico, por meio da educação para a cidadania e uma formação ao longo de toda a vida.. O ensino superior deve ser definido como um serviço público e não como uma empresa do saber e da formação orientada pelas leis de mercado."

Ao entendermos o ensino superior como um bem público e não como um bem privado, buscamos a igualdade de acesso de todos os indivíduos que tenham concluído o ensino básico. Esta é uma questão que envolve a participação das universidades, mas que, principalmente, envolve políticas governamentais e a participação de toda a sociedade. Em primeiro lugar, é necessário garantir o acesso de todos os indivíduos ao ensino fundamental e ao ensino médio em escolas públicas de boa qualidade. A deterioração da qualidade da escola pública nestes níveis de ensino é importante agravante nas condições de acesso ao ensino superior dos candidatos de menores condições econômicas. Outro fator importante é o ingresso precoce do jovem no mercado de trabalho. No acesso ao ensino superior, a maior discriminação que praticamos não é racial, ou religiosa, mas é fundamentalmente uma discriminação sócio-econômica.

As reformas educacionais não têm conseguido integrar os diferentes níveis de ensino e modificam as políticas da educação fundamental e média sem considerar as relações com o ensino superior. $\mathrm{O}$ ensino médio não deve ter por finalidade precípua preparar candidatos ao ensino superior, entretanto, constitui-se em pré-requisito necessário para tal acesso.

Por outro lado, a universidade deve investir na formação de docentes para a educação básica, oferecer cursos de reciclagem de curta duração, cursos de especialização, assegurando 
um processo de educação continuada dos professores. Aliás, esta é uma exigência maior da educação no século XXI: assegurar uma escola básica de qualidade, que estimule o gosto e o prazer de aprender, a capacidade de aprender a aprender e a curiosidade do espírito. A educação básica deverá combinar o ensino clássico com a realidade, permitido à criança e ao jovem o acesso às três dimensões da educação: ética e cultural, científica e tecnológica, econômica e social.

A universidade deverá investir no preparo de professores da educação básica no uso de novas tecnologias e na elaboração de material didático. Deverá ela própria fazer uso das novas tecnologias de informação e comunicação para, através do ensino à distância, facilitar e ampliar o acesso à formação permanente destes professores.

Não é permitido às universidades nos países emergentes e em desenvolvimento olvidarem as condições sócio-econômicas da sociedade a que pertencem e as conseqüentes necessidades de ingresso no mercado de trabalho dos jovens, que ocorre mais cedo do que em países desenvolvidos. Em muitos países, como o Brasil, o ensino superior tradicional é a principal alternativa de formação pós-educação básica. É premente a criação de oportunidades de educação e formação através de sistemas de educação mais diversificados, em cursos profissionais, técnicos, com média e curta duração, ministrados de forma tradicional, através de ensino à distância e outros. Tais programas de educação pós-educação básica, devem ampliar as possibilidades de ingresso no mercado de trabalho, sem alijar os que deles fizerem uso da continuidade dos seus estudos. Tais sistemas devem estar integrados com o ensino superior nas universidades, ligados de forma comunicante, permitindo-se a continuidade e a complementaridade da formação do indivíduo. Em nosso entendimento, tais programas não só reforçariam a igualdade de oportunidades como reduziriam a evasão no ensino superior.

As modernas tecnologias e seu potencial para educação constituem, também, um grande desafio que já se impõe às universidades na atualidade. O rápido desenvolvimento das tecnologias de informação e de comunicação constitui, ao mesmo tempo, um importante desafio de adaptar estas tecnologias às necessidades nacionais e regionais da educação e um poderoso instrumento a ser utilizado com fins educativos.

As modernas tecnologias de informação e de comunicação, além de revolucionarem as formas de elaboração, aquisição e transmissão do conhecimento, permitem a renovação dos métodos didáticos e pedagógicos e podem contribuir de forma significativa para ampliar o acesso à educação superior. 
A utilização desses instrumentos para o desenvolvimento acelerado dos programas de aprendizagem à distância deve se constituir em prioridade para facilitar e ampliar o acesso à educação, favorecendo a educação permanente e atingindo segmentos hoje marginalizados.

O uso intensivo de tecnologias da comunicação e da informação está transformando os conceitos clássicos da educação à distância, até então de uma separação física entre o aluno e o professor ou a instituição de ensino, para um conceito atual de aproximação ou mesmo de integração virtual entre os agentes dos processos de ensino-aprendizagem.

Esta mudança decorre da adoção de recursos tecnológicos e de estratégias de aprendizagem voltados para:

- a construção de ambientes virtuais de aprendizagem, utilizando, principalmente, a Internet e a videoconferência como meios para as atividades de alta interatividade;

- a teleconferência, os serviços de telefonia e de correio, para as atividades de média interatividade, complementados por materiais impressos;

- os CD-ROMs e as vídeo-aulas, como mídias de transmissão de conteúdos, atividades, exercícios de aprendizagem ou mesmo ambientes para aprendizagem por simulação ou imersão.

Assim, é possível uma educação à distância estruturada ora em bases de mídias integradas, ora em bases de convergência de mídias, conceitos que dominam a cena do uso de recursos tecnológicos na atualidade.

O cenário que se apresenta é o de intensificação de processos pela Internet, agregando performance multimídia na proporção do aumento da velocidade de conexão para o tráfego de dados para o usuário final.

O aumento contínuo de usuários conectados à Internet Brasil - que ocorre em paralelo à melhoria dos serviços de conexão, oferecidos pelos provedores de acesso, com saltos tecnológicos em velocidade de tráfego, sem uma correspondência de aumento linear dos custos - fortalece este cenário, pois agrega capilaridade, confiabilidade e economicidade para os serviços educacionais via rede.

Amplas são, também, as possibilidades que pode trazer a integração da tecnologia com o ensino proporcionado em sala de aula. Na Universidade Federal de Santa Catarina, os alunos dos Curso de Engenharia de Materiais já acessam da sua casa, via rede, experimentos realizados nos laboratórios situados no Campus, em tempo real. 
A revista "School News", em sua edição de fevereiro deste ano, traz a afirmação de que "o novo desafio dos administradores das instituições de ensino é encontrar professores que saibam como empregar os novos equipamentos computacionais dentro da sala de aula", ao comentar manifestação do "Forum on Educacional and Technology" sobre as estratégias para enfrentar o problema nos Estados Unidos. Entendemos que o grande desafio seja este: de preparar professores qualificados na integração entre ensino e tecnologia. Nossas universidades devem propiciar o acesso e o domínio destas novas tecnologias aos seus quadros discentes e docentes como condição necessária para uma participação ativa na sociedade do século que se inicia.

Um dos maiores desafios da gestão universitária é garantir os meios e recursos necessários para investir no seu quadro de pessoal de forma contínua, quer na capacitação e qualificação, quer nas condições de trabalho e remuneração. Assim, a atualização e a melhoria da competência pedagógica do corpo docente, através de programas que estimulem a permanente inovação nos métodos de ensino e aprendizagem e avaliação dos currículos, deve constituir-se em preocupação constante da administração das universidades.

As universidades são organizações peculiares, complexas e especializadas, que executam múltiplas atividades relacionadas às suas funções de ensino, pesquisa e extensão. Se as funções são indissociáveis, as atividades são muitas vezes interdependentes, e cada uma delas exige uma organização própria, diferente daquela necessária para as demais e para a organização com um todo. Isto requer, além da competência acadêmica, a preparação de pessoal docente e técnico-administrativo para o exercício das funções de administração e gestão universitárias.

$\mathrm{Na}$ Universidade Federal de Santa Catarina desenvolvemos, atualmente, dois programas na área de recursos humanos, com excelentes resultados: Programa de Educação Permanente para os Servidores da UFSC - PREPESUFSC e o Programa de Gestão Universitária - PROGEU. O primeiro é um programa de educação supletiva para servidores técnico, tendo formado já 150 alunos. O segundo programa compreende um curso de especialização e um curso de atualização em gestão universitária, voltados para servidores docentes e técnico-administrativos da Universidade.

Finalmente, é necessário não esquecer do foco principal da atenção da universidade: o estudante. Convém que recordemos as recomendações da Conferência Mundial sobre a Educação Superior, contidas na sua Declaração Mundial sobre a Educação Superior no século XXI: 
“Em um mundo em rápida transformação, é perceptível a necessidade de uma nova visão e um novo modelo de ensino superior, centrado no estudante. Isto exige reformas profundas, ampliação do acesso, bem como uma renovação dos conteúdos, métodos, práticas e meios de transmissão do saber, que deverão basear-se em novos tipos de vínculos e de colaboração com a comunidade e com os mais amplos setores da sociedade.

Para isto é necessário formular novos programas de estudo e utilizar métodos novos e adequados que permitam superar o mero domínio cognitivo das disciplinas, facilitar o acesso a novas propostas pedagógicas e didáticas e estimular a aquisição de conhecimentos práticos, competências e aptidões para a comunicação, a análise criativa e crítica, a reflexão independente e o trabalho em equipe num contexto multicultural, em situações em que a criatividade exige combinar o saber teórico e prático tradicional ou local com a ciência e a tecnologia de vanguarda."

O maior desafio da universidade, de qualquer nacionalidade e em qualquer época, é investir no seu maior capital: o capital humano. A universidade é o universo de pessoas que a integram.

Por isso, ao concluirmos, afirmamos a nossa compreensão de que a principal função da gestão universitária é a de coordenar o esforço cooperativo das pessoas que a compõem, isto é, docentes, técnico-administrativos e alunos, buscando alocar os recursos necessários para a concretização dos objetivos fins da instituição e zelando pelo compromisso social para com a sociedade que a mantém. 